\title{
ОСНОВАНИЯ НАСТУПЛЕНИЯ ГРАЖДАНСКО-ПРАВОВОЙ ОТВЕТСТВЕННОСТИ ЗА НАРУШЕНИЯ ПРАВ ПАЦИЕНТА В ОТНОШЕНИЯХ ПО ОКАЗАНИЮ МЕДИЦИНСКОЙ ПОМОЩИ С ПРИМЕНЕНИЕМ ТЕЛЕМЕДИЦИНСКИХ ТЕХНОЛОГИЙ
}

\section{GROUNDS FOR OFFENSIVE OF CIVIL LEGAL LIABILITY FOR VIOLATIONS OF PATIENT'S RIGHTS IN RELATIONSHIP ON PROVIDING MEDICAL CARE USING TELEMEDICAL TECHNOLOGIES}

\section{E. Karyagina}

Summary. Purpose: The purpose of this article is to comprehensively study the issues related to the grounds for the onset of civil liability in relations for the provision of medical care using telemedicine technologies.

Methods. The methods of this work were general scientific (system analysis method, universal dialectical, synthesis, induction and deduction) and special (formal legal, systemic structural, historical) methods.

Results:

1. The approaches to the definition of civil liability are analyzed, the concepts of "the basis of civil liability", "civil offense" are considered.

2. The rights of the patient under the specialized and consumer legislation are characterized.

3. A list of grounds for the occurrence of civil liability (civil offenses) for violations of the patient's rights in the provision of medical care (as well as medical services) has been compiled.

4. Five features of the provision of medical care with the use of telemedicine technologies, which are important for resolving the issue of the onset of civil liability, have been identified.

5. A list of grounds for the onset of civil liability for violations of patient rights in relations for the provision of medical care with the use of telemedicine technologies has been developed.

Conclusions:

1. Much that relates to the grounds for the onset of civil liability for violations of the patient's rights in a relationship to provide medical care (ordinary) is also inherent in the grounds for the occurrence of civil liability for violations of the patient's rights in relationships for the provision of medical care using telemedicine technologies. However, it is necessary to take into account the specifics of the relations in question to resolve the issue of imposing civil liability on the offender.
Карягина Екатерина Николаевна

Аспирант, ФГАОУ ВО «Казанский (Приволжский) федеральный университет», г. Казань

Аннотация. Цель. Цель настоящей статьи состоит в комплексном исследовании вопросов, связанных с основаниями наступления гражданско-правовой ответственности в отношениях по оказанию медицинской помощи с применением телемедицинских технологий.

Методы. Методами данной работы стали общенаучные (метод системного анализа, всеобщий диалектический, синтез, индукция и дедукция) и специальные (формально-юридический, системно-структурный, исторический) методы.

Результаты:

1. Проанализированы подходы к определению гражданско-правовой ответственности, рассмотрены понятия «основание гражданско-правовой ответственности», «гражданское правонарушение».

2. Охарактеризованы права пациента по специализированному и потребительскому законодательству.

3. Выстроен перечень оснований наступления гражданско-правовой ответственности (гражданских правонарушений) за нарушения прав пациента в отношениях по оказанию медицинской помощи (а также, медицинских услуг).

4. Выявлены пять особенностей оказания медицинской помощи с применением телемедицинских технологий, имеющих значение для разрешения вопроса о наступления гражданско-правовой ответственности.

5. Выведен перечень оснований наступления гражданско-правовой ответственности за нарушения прав пациента в отношениях по оказанию медицинской помощи с применением телемедицинских технологий.

Выводы:

1. Многое, что относится к основаниям наступления гражданско-правовой ответственности за нарушения прав пациента в отношениях по оказанию медицинской помощи (обычной), присуще и основаниям наступлениям гражданско-правовой ответственности за нарушения прав пациента в отношениях по оказанию медицинской помощи с применением телемедицинских технологий. Однако, необходимо учитывать специфику рассматриваемых отношений для разрешения вопроса о возложении гражданско-правовой ответственности на правонарушителя. 
2. The author of the work independently deduced a list of grounds for the onset of civil liability for violations of the patient's rights in relations with the provision of medical care using telemedicine technologies. The list reflects the features of these legal relations. However, it is not exhaustive and may be supplemented in the future.

Keywords: telemedicine technologies, medical care, patient, medical organization, consultant, civil offense, civil liability, grounds for offense.
2. Автором работы самостоятельно выведен перечень оснований для наступления гражданско-правовой ответственности за нарушения прав пациента в отношениях по оказанию медицинской помощи с применением телемедицинских технологий. Перечень отражает особенности данных правоотношений. Однако, он не является исчерпывающим и может быть дополнен в дальнейшем.

Ключевые слова: телемедицинские технологии, медицинская помощь, пациент, медицинская организация, консультант, гражданское правонарушение, гражданско-правовая ответственность, основания наступления. реди основных характеристик XXI века нередко отмечают информатизацию общества, а также внедрение новых технических возможностей в жизнь людей. Конец 10-х годов и начало 20-х годов этого столетия ознаменовался широкой цифровизацией общества, распространением электронных устройств, девайсов и беспроводных соединений - среди людей.

Новые технические возможности не могли не коснуться и одной из важнейших сфер жизни общества, а также одного из приоритетных направлений развития государства - системы здравоохранения. Их своего рода воплощением стали телемедицина и телемедицинские технологии.

Обращаясь к истории, отметим, что первые проявления телемедицины теоретической медицине известны еще с середины XIX века [1, с. 165]. В научной литературе термин «телемедицина» упоминается с 70-х годов XX века [1, с. 166]. А первые практические шаги по использованию телемедицины в России были сделаны еще во времена СССР (60-е года XX века) и выразились в телеметрической записи «физиологических показателей у первых космонавтов» $[7$, с. 45].

Тем не менее, долгое время отсутствовали правовые нормы, регулирующие применение телемедицины. Ситуация изменилась с 1 января 2018 года. А именно, вступили в силу изменения в Федеральном законе от 21 ноября 2011 г. № 323-Ф3 «Об основах охраны здоровья граждан в Российской Федерации» [20] (далее по тексту - Ф3 № 323-Ф3). Было регламентировано понятие «телемедицинских технологий», установлены особенности оказания медицинской помощи с применением телемедицинских технологий.

На сегодняшний день со дня вступления в силу данных изменений прошло 3,5 года. Однако, до сих пор отсутствует реальная судебная практика по применению новых законоположений. Медицинская практика также пока еще складывается. И остается немало неразъясненных вопросов в части реализации данных правовых норм, их корректного понимания и использования.

В связи с вышесказанным, по-прежнему являются актуальными и имеющими теоретическую и практическую значимость исследования в области правового регулирования отношений по оказанию медицинской помощи с применением телемедицинских технологий.

Одними из ключевых вопросов в рассматриваемой сфере отношений можно назвать вопросы ответственности, в том числе, гражданско-правовой. Значение изучения проблем гражданско-правовой ответственности в отношениях по оказанию медицинской помощи с применением телемедицинских технологий определяется не только важнейшими функциями ответственности, но и тем, что вопросы ответственности в исследуемых отношениях не получили должного нормативно-правового разъяснения и, как следствие, порождают ряд теоретических и практических проблем.

Настоящая статья посвящена основаниям наступления гражданско-правовой ответственности за нарушения прав пациента в отношениях по оказанию медицинской помощи с применением телемедицинских технологий.

Гражданско-правовая ответственность - один из центральных институтов гражданского права. В российской цивилистике является предметом дискуссий и объектом научных работ еще с XIX века. Например, гражданско-правовая ответственность исследовалась учеными казанской цивилистической школы - Д.И. Мейером и Г.Ф. Шершеневичем. Д.И. Мейер анализировал ее сущность в разрезе нарушения права, Г.Ф. Шершеневич - в части вопросов, связанных с обязательствами, основанными на гражданском правонарушении [6, с. 29].

Существуют различные определения гражданско-правовой ответственности. В силу выбранной темы данной статьи мы не будем подробно останавливаться на каждом из них. Однако, выделим два наиболее часто встречаю- 
щихся варианта понимания гражданско-правовой ответственности.

Согласно первому из них, гражданско-правовая ответственность трактуется как мера (форма) государственного принуждения [15, с. 445]. В соответствии со вторым, гражданско-правовая ответственность представляет собой санкцию за правонарушение [5, с. 141].

Сложно сказать, какая из этих точек зрения больше отражает суть гражданско-правовой ответственности. Каждая является верной. Тем не менее, автор больше склоняется к первой из них.

Гражданско-правовая ответственность как мера (форма) государственного принуждения является также более подходящим определением и для рассматриваемых отношений. Ведь оказание медицинской помощи с применением телемедицинских технологий напрямую связано с жизнью и здоровьем пациента. А сохранение и улучшение жизни и здоровья людей, система здравоохранения в целом являются одними из приоритетных направлений развития государства и государственной политики.

Значение гражданско-правовой ответственности для исследуемых правоотношений определяется выполняемыми ею функциями. Главной функцией гражданско-правовой ответственности называют компенсаторно-восстановительную [15, с. 446]. Также, к ее функциям можно отнести штрафную, стимулирующую, сигнализационную $[17$, c. 99].

Для отношений по оказанию медицинской помощи с применением телемедицинских технологий, как и для многих других видов правоотношений, наиболее важную роль, по нашему мнению, играет компенсаторно-восстановительная функция гражданско-правовой ответственности. Ведь когда было допущено нарушение прав пациента, выразившееся, например, в причинении вреда его здоровью, первоочередное значение имеет компенсация и восстановление. Все остальные функции, хотя и имеют определенно весомую значимость, скорее уходят на второй план.

Ключевым аспектом при разрешении вопроса о том, наступит ли гражданско-правовая ответственность, является вопрос о ее основаниях и условиях. Этот же вопрос, безусловно, касается и исследуемых отношений.

Периодически «основание» («основания») и «условия» в литературе называют синонимами. Безусловно, мы не согласны с такой позицией, ведь данные понятия имеют совершенно разную «смысловую нагрузку» [3, с. 963]. Каждое из них играет свою роль для гражданско-правовой ответственности.
В этой связи в настоящей статье мы рассмотрим только одну из частей данного вопроса и применительно к анализируемой сфере правоотношений - основания наступления гражданско-правовой ответственности за нарушения прав пациента в отношениях по оказанию медицинской помощи с применением телемедицинских технологий.

Как указывали В.Т. Смирнов и А.А. Собчак, «основание - это то, что порождает какое-либо явление, фундамент, на который последнее опирается и который определяет его природу» [18, с. 56]. Данное определение показывает краеугольное значение «основания» для возложения гражданско-правовой ответственности на правонарушителя.

Основанием гражданско-правовой ответственности является «совершение правонарушения, предусмотренного законом или договором» [15, с. 452]. Например, это может быть ненадлежащее исполнение договорных обязанностей. Однако, правонарушение - это не единственное основание наступления гражданско-правовой ответственности. Основаниями также могут быть и «иные обстоятельства, прямо предусмотренные законом или договором» [15, с. 453]. В качества варианта таких обстоятельств Е.А. Суханов приводит ответственность за действия третьих лиц (ответственность поручителя) [15, C. 452].

Интересно отметить то, что несмотря на то, что совершение правонарушения является, можно сказать, главным основанием наступления гражданско-правовой ответственности, законодательного определения «гражданского правонарушения» не существует. По нашему мнению, это является большим недостатком. На это же указывают и многие ученые: например, И.В. Маштаков [8, с. 29], Н.Н. Вопленко [2, с. 6].

Еще дореволюционный цивилист И.А.Покровский указывал на «чрезвычайные трудности» В определении «гражданского правонарушения» [12, с. 278], не умаляя при этом его значимости для возложения ответственности, и предпринимал усилия для анализа данного понятия.

В связи с отсутствием законодательного определения «гражданского правонарушения», важностью и при этом сложностью данного понятия, научные исследования, посвященные «гражданскому правонарушению», продолжились и в дальнейшем. В результате чего, появилось немало вариантов трактования этого термина. В настоящей работе мы не будем подробно останавливаться на них. Но выделим наиболее содержательные из них, которые, по нашему мнению, играют весомую роль для характеристики оснований наступления гражданско-правовой 
ответственности за нарушения прав пациента в отношениях по оказанию медицинской помощи с применением телемедицинских технологий.

Согласно точке зрения В.Л.Слесарева, гражданское правонарушение - это «противоправное действие (бездействие), посягающее на общественные отношения, урегулированные нормами гражданского права» $[17$, с. 5].

По мнению И.С. Самощенко и М.Х. Фарукшина, гражданское правонарушение представляет собой «общественно опасное (или вредное) виновное деяние (действие или бездействие), нарушающее нормы права, за которое установлены меры юридической ответственности» $[16$, с. 74$]$.

Теперь непосредственно перейдем к анализу оснований наступления гражданско-правовой ответственности в рассматриваемых отношениях.

Прежде всего, следует сказать, что оказание медицинской помощи с применением телемедицинских технологий - не отдельный вид медицинской деятельности [10]. По существу, это лишь один из способов дистанционного оказания медицинской помощи [19, с. 92]. Поэтому можно утверждать, что многое, что относится к основаниям наступления гражданско-правовой ответственности при оказании медицинской помощи (обычной), присуще и исследуемой сфере отношений.

Однако, очень важно учитывать специфику медицинской помощи, оказываемой с применением телемедицинских технологий, а также ограничения, установленные законодательством в отношении нее. Например, запрет на постановку диагноза онлайн (п. 3 статьи 36.2 Ф3 № 323Ф3 [20], п. 47 Приказа Минздрава РФ от 30.11.2017 № 965н «Об утверждении порядка организации и оказания медицинской помощи с применением телемедицинских технологий» [14] (далее - Приказа № 965-н)) уже является большим отличием и особенностью при разрешении вопросов наступления гражданско-правовой ответственности.

Для того чтобы охарактеризовать основания наступления гражданско-правовой ответственности в рассматриваемых отношениях, остановимся вначале на общих основаниях наступления гражданско-правовой ответственности за нарушения прав пациента при оказании медицинской помощи.

Говоря о правах пациента, за нарушения которых может наступить гражданско-правовая ответственность, отметим, что существуют различные научные классификации прав пациента. Например, А.Н. Пищита выделяет 4 группы прав пациента: общие права; права в области ме- дицинского страхования; права при оказании различных видов медицинской помощи; права различных профессиональных и социальных категорий пациентов [11, с. 56].

В настоящей работе мы не будем останавливаться на классификациях прав пациента. Но выделим основные права пациента при оказании медицинской помощи. Так, согласно п. 5 статьи 19 Ф3 № 323-Ф3 [20], пациент имеет право на: выбор врача и выбор медицинской организации; профилактику, диагностику, лечение, медицинскую реабилитацию в медицинских организациях в условиях, соответствующих санитарно-гигиеническим требованиям; получение консультаций врачей-специалистов; облегчение боли, связанной с заболеванием, состоянием и (или) медицинским вмешательством, методами и лекарственными препаратами; получение информации о своих правах и обязанностях, состоянии своего здоровья; получение лечебного питания в случае нахождения пациента на лечении в стационарных условиях; защиту сведений, составляющих врачебную тайну; отказ от медицинского вмешательства; возмещение вреда, причиненного здоровью при оказании ему медицинской помощи и др. Также, в соответствии со статьей 20 Ф3 № 323-Ф3 [20], пациент дает информированное добровольное согласие на медицинское вмешательство или отказ от него. Следовательно, у пациента также есть право на дачу информированного добровольного согласия на медицинское вмешательство или отказ от него.

Кроме того, пациент является потребителем платных медицинских услуг, а также медицинских услуг, предоставляемых в рамках добровольного и медицинского страхования (в соответствии с п. 9 Постановление Пленума Верховного Суда РФ от 28.06.2012 № 17 «О рассмотрении судами гражданских дел по спорам о защите прав потребителей» [13]). Поскольку, согласно пп. 3 п. 1 статьи 2 Ф3 № 323-Ф3 [20], медицинская помощь включает в себя предоставление медицинских услуг, при характеристике прав пациента при оказании медицинской помощи необходимо учитывать и права пациента как потребителя медицинских услуг.

Согласно Закону РФ от 07.02.1992 № 2300-1 «О защите прав потребителей» [4] (далее - 3ПП), пациент как потребитель медицинских услуг, имеет, определенные права. Так, в соответствии с общими положениями главы I 3ПП [4] пациент-потребитель имеет право на: качественные услуги; безопасные услуги; получение необходимой и достоверной информации об услугах и об исполнителе, возмещение вреда, причиненного жизни, здоровью вследствие необеспечения безопасности услуг, непредставления полной и достоверной информации об услугах, вследствие недостатков; возмещение убытков; взыскание неустойки; компенсацию морального вреда; судебную защиту и др. 
Согласно главе III 3ПП, посвященной защите прав потребителей при выполнении работ (оказании услуг) [4], пациент-потребитель имеет право на оказание услуг в срок, установленный правилами выполнения услуг или договором об оказании услуг; права при нарушении срока выполнения услуг; права при обнаружении недостатков, право на отказ от исполнения договора.

На основании вышеизложенного, можно выделить следующие возможные нарушения прав пациента (гражданские правонарушения), которые могут являться основаниями для наступления гражданско-правовой ответственности в отношениях по оказанию медицинской помощи (а также, медицинских услуг):

- несоответствие качества оказанной медицинской помощи установленным стандартам и порядкам ее оказания (иными словами, некачественное оказание медицинской помощи, в том числе, медицинских услуг);

- несоответствие оказанной медицинской помощи условиям и стандартам безопасности (небезопасное оказание медицинской помощи, в том числе, медицинских услуг);

- оказание медицинской помощи в условиях, не соответствующих санитарно-гигиеническим требованиям;

- применение методов лечения, приносящих дополнительную боль пациенту при возможности их исключения или применения более щадящих - для облегчения боли пациенту;

- непредоставление информации, предоставление недостоверной информации или предоставление информации не в полном объеме пациенту - о его правах и обязанностях, о состоянии здоровья, об оказываемой медицинской помощи (медицинских услугах), в том числе, о ее методах, рисках, последствиях, об исполнителе (медицинской организации);

- неполучение от пациента информированного добровольного согласия на медицинское вмешательство или отказ от него, а также нарушение порядка его получения;

- разглашение сведений, составляющих врачебную тайну;

- нарушение права пациента на выбор врача для оказания медицинской помощи при возможности такого выбора;

- нарушение сроков оказания медицинской помощи (медицинских услуг);

- необоснованное взимание платы за дополнительные медицинские услуги, которые были намеренно навязаны исполнителем;

- оказание медицинских услуг, не соответствующих по объему установленной в договоре цене;
- иные нарушения прав пациента со стороны врачей, медицинских работников, медицинской организации, приносящие вред пациенту.

Следует отметить, что правам пациента корреспондируют определенные обязанности врачей и медицинских работников, которые оказывают медицинскую помощь пациенту, а также обязанности медицинской организации, в которой работают данные врачи и медицинские работники (за исключением частнопрактикующих врачей) и в которой оказывается данная медицинская помощь. Поэтому можно утверждать, что гражданско-правовая ответственность наступает за ненадлежащее исполнение или неисполнение обязанностей медицинской организации, предоставляющей медицинскую помощь (медицинские услуги) пациенту, а также за нарушение профессиональных обязанностей медицинскими работниками, если это повлекло причинение вреда пациенту [8, с. 56]. Так, ненадлежащим исполнением обязанностей медицинской организации, предоставляющей медицинские услуги, является нарушение срока оказания медицинских услуг (статья 27 3ПП [4] или оказание медицинских услуг с недостатками (статьи 4, 29 3ПП [4]). Примером нарушения профессиональных обязанностей медицинских работников является несоблюдение врачебной тайны (пп. 2 п. 2 статьи 73 Ф3 № 323-Ф3 [20]).

Как уже говорилось выше, многое, что относится к основаниям наступления гражданско-правовой ответственности при оказания медицинской помощи, присуще и исследуемым правоотношениях по оказанию медицинской помощи с применением телемедицинских технологий. Однако, прежде чем выявить искомый перечень, необходимо остановиться на особенностях оказания медицинской помощи с применением телемедицинских технологий.

Во-первых, медицинская помощь (в том числе, медицинские услуги), с применением телемедицинских технологий, оказывается либо в формате дистанционных медицинских консультаций (в том числе, медицинских консилиумов врачей), либо в виде дистанционного наблюдения за пациентом. Иными словами, способы оказания такой медицинской помощи ограничены законом (статья 36.2 Ф3 № 323-Ф3 [20]).

В-вторых, консультации с применением телемедицинских технологий проводятся в строго ограниченных целях (п. 2-3 статьи 36.2 Ф3 № 323-Ф3 [20], а дистанционное наблюдение за состоянием здоровья пациента может проводиться только после очного приема (п. 4 статьи 36.2 Ф3 № 323-Ф3 [20]).

Во-третьих, как уже замечалось ранее, первичная постановка диагноза и соответственно первичное на- 
значение лечения при оказании медицинской помощи с применением технологий без очного приема пациента - запрещено (п. 47 Приказа Минздрава № 965-н [14]). Хотя при этом, раздел III Приказа Минздрава № 965-н [14] уточняет, что телемедицинские технологии могут использоваться при всех видах, формах и любых условиях оказания медицинской помощи.

В-четвертых, при оказании медицинской помощи с применением телемедицинских технологий появляются новые субъекты (участники) правоотношений: консультант (врач-консультант), врачи - участники консилиума, консультирующая медицинская организация, организация, являющаяся оператором информационных систем. Соответственно, у каждого из названных субъектов есть свои права и обязанности. Неисполнение или ненадлежащее исполнение этих обязанностей, если оно непосредственно связано с оказанием медицинской помощи с применением телемедицинских технологий и повлекло причинение вреда пациенту, может стать основанием наступления гражданско-правовой ответственности. Например, такими основаниями могут быть: нарушение врачом-консультантом / консультирующей медицинской организацией сроков оказания телемедицинских консультаций (п. 18-21 Приказа Минздрава № 965-н [14]); неоформление или ненадлежащее оформление медицинского заключения по результатам проведения консультации (п. 24, 32 Приказа Минздрава № 965-н); непредоставление или ненадлежащее предоставление пациенту консультирующей медицинской организацией, а также организацией, являющейся оператором иных информационных систем информации в доступной форме, в соответствии с требованиями п. 46 Приказа Минздрава № 965-н [14] и др.

B-пятых, при оказании медицинской помощи с применением телемедицинских технологий дополнительные обязанности появляются у лечащего врача и, соответственно, медицинской организации, в которой работает этот лечащий врач и обслуживается пациент. Данные дополнительные обязанности установлены Приказом Минздрава № 965-н [14]. Нарушения исполнения данных дополнительных обязанностей, причинившие вред пациенту, также могут повлечь гражданско-правовую ответственность.

Итак, подводя итог всему вышесказанному, далее перечислим основания наступления гражданско-правовой ответственности за нарушения прав пациента в отношениях по оказанию медицинской помощи с применением телемедицинских технологий. Такими основаниями могут быть:

- несоответствие качества оказанной медицинской помощи с применением телемедицинских технологий (в том числе, медицинских консультаций (консилиумов врачей) и дистанционного наблюде- ния за состоянием здоровья пациента) установленным стандартам и порядкам ее оказания (иными словами, некачественное оказание медицинской помощи с применением телемедицинских технологий);

- несоответствие оказанной медицинской помощи с применением телемедицинских технологий условиям и стандартам безопасности (небезопасное оказание медицинской помощи с применением телемедицинских технологий);

- оказание медицинской помощи с применением телемедицинских технологий в условиях, не соответствующих санитарно-гигиеническим требованиям (в случае, если пациент находится в медицинской организации при оказании данной помощи);

- назначение и/или использование при коррекции лечения при оказании медицинской помощи с применением телемедицинских технологий методов лечения, приносящих дополнительную боль пациенту при возможности их исключения или применения более щадящих - для облегчения боли пациенту;

- непредоставление информации, предоставление недостоверной информации или предоставление информации не в полном объеме пациенту - о его правах и обязанностях, о состоянии здоровья, об оказываемой медицинской помощи с применением телемедицинских технологий, в том числе, о ее методах, рисках, последствиях, о консультирующей медицинской организации, о консультанте и иной информации, которая должна быть предоставлена;

- неполучение от пациента информированного добровольного согласия на медицинское вмешательство или отказ от него, а также нарушение порядка его получения - при оказании медицинской помощи с применением телемедицинских технологий;

- разглашение сведений, составляющих врачебную тайну, которые были получены при оказании медицинской помощи с применением телемедицинских технологий;

- нарушение права пациента на выбор врача-консультанта для оказания медицинской помощи с применением телемедицинских технологий при возможности такого выбора;

- нарушение сроков оказания медицинской помощи с применением телемедицинских технологий;

- необоснованное взимание платы за дополнительные медицинские услуги, которые были намеренно навязаны исполнителем при оказании медицинской помощи с применением телемедицинских технологий;

- оказание медицинской помощи с применением телемедицинских технологий, не соответствующих по объему установленной в договоре цене; 
- иные нарушения прав пациента, возникшие при оказании медицинской помощи с применением телемедицинских технологий со стороны консультанта, лечащего врача, иных медицинских работников, консультирующей медицинской организации, медицинской организации, к которой относится лечащий врач пациента (при несовпадении с консультирующей медицинской организацией), оператора информационных систем, которые повлекли причинение вреда пациенту.

Следует отметить, что данный перечень оснований гражданско-правовой ответственности за нарушения прав пациента при оказании медицинской помощи с применением телемедицинских технологий не является исчерпывающим (в связи с чем, в конце использована формулировка «иные нарушения»). Во-первых, остается немало неразрешенных законодателем вопросов по применению телемедицинских технологий. Во-вторых, практика (в том числе, судебная) до сих пор не сформировалась. Остается неясным, как и в каких случаях реально будет возлагаться гражданско-правовая ответственность на нарушителя в рассматриваемых отношениях. В-третьих, указанный перечень будет совершенствоваться и, возможно, пополняться в наших дальнейших научных исследованиях по данной тематике.

\section{ЛИТЕРАТУРА}

1. Варюшин М.С. Правовое регулирование телемедицины в России и ЕС: два шага вперед и один назад // «Закон».— 2018.— № 1.—C. 165-174.

2. Вопленко, Н.Н. Общественная опасность или социальная вредность? // Вестн. Волгоград. гос. ун-та. Сер. З. Экономика. Право.— Волгоград, 1997.— Вып. 2.- С. 6-10.

3. Гражданское право: учеб.: в 3 т. Т. 1. / Е.Н. Абрамова, Н.И. Аверченко, Ю.В. Байгушева [и др.]; под ред. А.П. Сергеева. — М.: ТК Велби, $2009 .-1008$ с.

4. Закон РФ от 07.02.1992 № 2300-1 (ред. от 22.12.2020) «0 защите прав потребителей» // «Российская газета».— 1996. — 16 января.— № 8.

5. Иоффе 0.С. Избранные труды: В 4 т. Т.ІІІ. Обязательственное право. — СПб.: Юридический центр Пресс, 2004. — 837 с.

6. Карягина Е.Н., Арсланов К.М. Формирование традиций в исследовании вопросов гражданско-правовой ответственности в Казанском университете (на примере трудов Д.И. Мейера и Г.Ф. Шершеневича). // Традиции юридической науки в Казанском университете глазами студентов и преподавателей: сборник совместных научных статей преподавателей и студентов юридического факультета Казанского (Приволжского) федерального университета.— Казань: Изд-во Казан. ун-та, 2015.- С. 28-33.

7. Куделина 0.В., Хлынин С.М. Медицинская информатика. Томск: СибГмУ, 2009. - 83 с.

8. Маштаков И.В. Гражданское правонарушение: определение понятия и юридические признаки. — Вестник Самарской гуманитарной академии. Серия «право».— 2007.— № 2.- С. 29-35.

9. Медицинское право: Учебное пособие. - М.: Статут, 2019. - 190 с.

10. Письмо Министерства здравоохранения РФ от 9 апреля 2018 г. № 18-2/0579 «0 разъяснении порядка организации и оказания медицинской помощи с применением телемедицинских технологий» (Документ официально опубликован не был) // [Электронный pecypc] — URL: http://base.garant. ru/71942326/ (дата обращения: 29.04.2021).

11. Пищита А.Н. Правовой статус российского пациента // Журнал российского права. - 2005. — № 11. — С. 46-53.

12. Покровский И.А. Основные проблемы гражданского права. М.: (татут (в серии «Классика российской цивилистики»), 1998. - 353 с.

13. Постановление Пленума Верховного Суда РФ от 28.06.2012 № 17 «0 рассмотрении судами гражданских дел по спорам о защите прав потребителей» // Российская газета. — 2012. - 11 июля.— № 156.

14. Приказ Минздрава России от 30.11.2017 № 965н «0б утверждении порядка организации и оказания медицинской помощи с применением телемедицинских технологий» (Зарегистрировано в Минюсте России 09.01.2018 № 49577) // Официальный интернет-портал правовой информации — URL: http://www.pravo.gov.ru, 10.01.2018 (дата обращения: 29.04.2021).

15. Российское гражданское право: Учебник: В 2 т. Т. І: 0бщая часть. Вещное право. Наследственное право. Интеллектуальные права. Личные неимущественные права / Отв. ред. Е.А. Суханов. — 2-е изд., стереотип. - М.: Статут, 2011.— 958 с.

16. Самощенко И.С., Фарукшин М.Х. Ответственность по советскому законодательству. М., 1971. - 240 с.

17. Слесарев В.Л. Объект и результат гражданского правонарушения. - Томск, 1980. - 166 с.

18. Смирнов В.Т., Собчак А.А. Общее учение о деликтных обязательствах в советском гражданском праве. Л.: Изд-во Ленингр. ун-та, 1983. - 152 с.

19. Смирнова Е.А., Шишанова А.А. Телемедицина в новых правовых реалиях // Журнал телемедицины и электронного здравоохранения. 2018. C. 91-97. URL: http://jtelemed.ru/article/telemedicina-v-novyh-pravovyh-realijah (дата обращения: 29.04.2021).

20. Федеральный закон от 21 ноября 2011 г. № 323-Ф3 (ред. от 22.12.2020) «06 основах охраны здоровья граждан в Российской Федерации» // Российская газета. - 2011. - 23 ноября.— № 263.

(с Карягина Екатерина Николаевна 